\title{
PAST AND FUTURE TRENDS IN WORLD ECONOMIC DEVELOPMENT
}

CIR GEORGE NELSON assumed office as president of the Institution of Electrical Engineers on October 6 and delivered his inaugural address on the evening of that day. In this address, Sir George outlined the course of development of the application of electricity to the needs of the community from the time of the inception of the Institution in 1871 to the present day, and he related this development to the main changes of social and economic environment which have taken place in that interval. From the present day, he then viewed the future prospect.

For Great Britain in 1905 , the installed capacity of generating plant represented $1 / 20 \mathrm{~kW}$. per head of population, while for the United States the corresponding figure was $1 / 12 \mathrm{~kW}$. These figures have risen in the intervening fifty years to $\frac{1}{2} \mathrm{~kW}$. and $\frac{3}{4} \mathrm{~kW}$., respectively. It has been forecast in a paper read at the recent Atomic Energy Conference at Geneva that the next fifty years would see a threefold increase in the total energy consumption of the world. Already, it is recognized that the world's demands for power will very quickly exhaust the conventional sources of energy, in particular the natural fuels; but the solution of this problem is in sight in the utilization of nuclear energy. This growing demand for power, which is reflected in both the increase in world population and the universal urge to improve standards of living, is, however, accompanied by correspondingly increased consumptions of the basic constructional materials.

Some 90 per cent of the world's present population has a standard of living below that of the United States and Great Britain, and it has been estimated that, if the living stendard of the whole world were raised instantly to that of Great Britain, the resources of such basic materials as iron and copper would last only twenty-five years. Although such a rate of exhaustion is far outside practical possibility, considerations such as these do indicate an urgent need, namely, that of producing synthetically basic metals and similar materials.

The most notable development up to the present time in the field of artificial substitutes is the cellulose products. 'Terylene' fibres, for example, have physical properties comparable with those of steel. It is possible that, in time, means may be found of producing economically a substitute for steel for structural purposes, which would render it possible to conserve iron ore for the manufacture of magnetic or such other special-purpose steels. Synthetic materials have also been produced suitable for the manufacture of pipes for carrying hot, cold or corrosive liquids. Such pipes can serve as a substitute for copper or lead pipes and help to conserve the supplies of these metals.

If a lowering of the standard of living due to the exhaustion of natural resources is to be avoided, intensive effort must be devoted to the production of synthetic substitutes of all kinds, and Sir George pointed out that this effort must be made now. The movement of the whole front of technolngical advarice, whether in the generation of power, the manufacture of synthetic materials, or in the application of automatic methods of production, is dependent upon the supply of scientific workers and technologists. The shortage of scientific man-power is one of the major problems confronting Great Britain and the Commonwealth, and the Institution of Electrical Engineors has its contribution to make towards the solution of the problem.

Sir George reviewed some of the efforts which are being made to increase the intake of suitable young men to the engineering profession. Ho spoke with appreciation of the film entitled "The Enquiring Mind", which has been produced with the object of attracting the attention of parents and boys to the opportunities for careers in the fields of applied science and technology. It is particularly necessary, he suggested, to attract a great proportion of the young people who at present choose to pursue the Arts. There is also an urgent need for technically qualified men who have natural gifts for management and highest administration. Such qualities are inborn, and the aim should be to develop these natural gifts, when found, in association with a scientific or technical education. Sir George regretted that he could not provide a formula for the early identification of men with this gift, but he suggested that careers masters in schools could make a notable contribution in this connexion.

\section{YEAST MITOCHONDRIA}

\section{Subcellular Units involved in the Synthesis of Respiratory Enzymes in Yeast}

TN a series of papers from this laboratory published 1 in $1949^{1}$, it was shown that clones of normal yeast during their growth constantly give rise to respiration. deficient mutants ('vegetative mutants') stable in vegetative reproduction. The respiratory deficiency was shown to be due to lack of several enzymes (including cytochrome oxidase) bound, in normal yeast, to particles which can be sedimented by centrifugation, and to behave as a non-Mendelian character in crosses between normal and mutant yeast. It was suggested ${ }^{2}$ that the mutation consists in the loss or irreversible functional inactivation of a particulate cytoplasmic auto-reproducing factor, and the question of the possible identity of this factor with subcellular units defined by various biochemical and cytological criteria was discussed.

Our observations have been reproduced and extended by several authors (cf. ref. 3) and have been the subject of several reviews in which our own views concerning the problems of the nature of the mutation giving rise to the 'vegetative mutants' on one hand, and that of the identity of the cytoplasmic factor on the other, have sometimes been misinterpreted. The purpose of the present communication is to restate our position regarding these two problems.

In discussing these problems, the following units, each defined by independent criteria, must be taken 